\title{
Assessment of Polymeric Nanoparticles to Enhance Oral Bioavailability and Antioxidant Activity of Resveratrol
}

\author{
R. HASIJA ${ }^{1}$, S. CHAURASIA² AND SWATI GUPTA*
}

Department of Pharmaceutics, Amity Institute of Pharmacy, Amity University, Noida, Uttar Pradesh 201301, ${ }^{1}$ Formulation Research and Development, Mankind Research Centre, Gurgaon, Haryana 122050, ${ }^{2}$ Innovation and Pharma Research and Development, Ashland Specialty Ingredients, Hyderabad, Telangana 500078, India

Hasija et al.: Assessment of Resveratrol Loaded Polymeric Nanoparticles

\begin{abstract}
Resveratrol has proven as potential natural antioxidant, non-flavonoid polyphenolic compound, but it has limitations such as low water solubility, which substantially restricts oral bioavailability. To enhance oral bioavailability and antioxidant potential of resveratrol by fabricating the resveratrol encapsulated oral eudragit $^{\circledR}$ E100 based polymeric nano-delivery system. Resveratrol-encapsulated polymeric nanoparticles were developed by solvent extraction and diffusion method. Copolymer, eudragit ${ }^{\circledR}$ E100 polymeric matrices were used to prepared polymeric nanoparticles and in vitro physicochemically characterized. Furthermore, in vivo pharmacokinetic and antioxidant potential of optimized resveratrol-encapsulated polymeric nanoparticles was evaluated. The resveratrol-encapsulated polymeric nanoparticles exhibited optimum mean particle size $(410 \pm 9.78 \mathrm{~nm})$, polydispersity index $(0.203 \pm 0.079)$ and encapsulation efficiency $(66.88 \pm 5.45 \%)$, respectively. In vitro release profile of resveratrol showed $>25 \%$ release in first $2 \mathrm{~h}$ in phosphate-buffered saline $\mathrm{pH} 7.4$ followed by $>75 \%$ at the end of $48 \mathrm{~h}$. The optimized resveratrolencapsulated polymeric nanoparticles were stable at the accelerated condition and room temperature, respectively. The optimized resveratrol-encapsulated polymeric nanoparticles demonstrated significantly higher oral bioavailability $(\sim 4.07$-fold; $p<0.05)$ as compared to pure resveratrol. Furthermore, the optimized resveratrol-encapsulated polymeric nanoparticles were evaluated for free radical scavenging activity and showed to increase the activity with time i.e. after $72 \mathrm{~h}$, it was the same as pure resveratrol but at $24 \mathrm{~h}$ no increase in antioxidant activity was observed with optimized resveratrol-encapsulated polymeric nanoparticles. Furthermore, half-maximal inhibitory concentration of the optimized resveratrolencapsulated polymeric nanoparticles was decreased with time. Results are suggesting that resveratrolencapsulated polymeric nanoparticles are the promising approach using eudragit ${ }^{\circledR} \mathbf{E} 100$ as a polymeric material to enhance oral bioavailability and antioxidant potential of insoluble resveratrol.
\end{abstract}

Key words: Resveratrol, eudragit ${ }^{\circledR}$ E100, oral polymeric nanoparticles, bioavailability, antioxidant activity

The oxygen metabolism produces exogenous factors or by-products, which repeatedly produce the Reactive Oxygen Species (ROS) inside the human body ${ }^{[1]}$. However, high concentrations of ROS, oxidative stress can stimulate damage of Deoxyribonucleic Acid (DNA), activate cancer cells, degeneration, vascular and other diseases ${ }^{[2]}$. Many antioxidants are shown promising additional beneficial cellular effects through modulation processes at specific biochemical levels such as protein synthesis and signaling pathways ${ }^{[3]}$. Therefore, to neutralize high production of ROS and reduce oxidative stress by externally supplied enzymes, antioxidant and endogenous factors are used such as superoxide dismutase, catalase and glutathione

*Address for correspondence

E-mail: sgupta24@amity.edu

November-December 2021 peroxide $^{[4]}$. However, the novel antioxidant is being screened from natural and synthetic sources ${ }^{[5]}$.

The use of exogenous antioxidant, mainly naturally derived compounds have acknowledged an enormous interest in the modern era for their prophylactic and therapeutic potential against ROS is compromised. The natural, non-flavonoid polyphenolic compound i.e. trans-Resveratrol (Res), mainly present in more

\footnotetext{
This is an open access article distributed under the terms of the Creative Commons Attribution-NonCommercial-ShareAlike 3.0 License, which allows others to remix, tweak, and build upon the work non-commercially, as long as the author is credited and the new creations are licensed under the identical terms
}

Accepted 06 November 2021

Revised 19 July 2021

Received 01 December 2020

Indian J Pharm Sci 2021;83(6):1114-1128 
than 70 plant species, including human foods such as grapes, peanuts, Japanese knotweed, Itadori tea, soy and red fruits ${ }^{[6-8]}$ is used. Many studies have been demonstrated that Res shows numerous desirable biological activities including high antioxidant activity $^{[9]}$, anti-inflammatory, cardioprotection, antiplatelet aggregation, vasodilation, antiviral activity, prolongation of lifespan, neurodegenerative diseases, estrogenic functions and cancer chemoprotective activity ${ }^{[10-14]}$. Apart from the numerous therapeutic activity in several experimental models, the clinical applications of Res have been restricted because of its low water solubility $(\sim 3 \mathrm{mg} / 100 \mathrm{ml})$ and $\log \mathrm{P} \sim 3.1^{[15]}$. Despite the poor water solubility of Res, its membrane permeability is quite high and can come under class II compound in the biopharmaceutical classification system $^{[16]}$. Therefore, beneficial application of Res remains very restricted due to its short biological half-life, labile properties, quick metabolism and elimination $^{[17]}$ indicate that the deprived bioavailability (approximately $<1.0 \%$, when orally administered), thereby limit the use of Res in therapeutic systems ${ }^{[18]}$. After oral administration of Res, the plasma half-life was found to be only $15 \min ^{[19,20]}$. Moreover, Res is a polyphenolic compound containing hydroxyl groups (3, 5,40 -positions of the stilbene moiety) which is suitable substrates for conjugation reactions i.e. glucuronidation and sulfation thereby Res extensively metabolized in phase $I^{[21-23]}$. Although several strategies have been adopted to rectify the troubles interrelated with a half-life, in vitro release, intensive metabolism and bioavailability problems of Res such as solid lipid nanoparticles, biodegradable Polymeric Nanoparticles (PNPs), liposomes, micro and nanoemulsions technique is used ${ }^{[21]}$. Apart from these strategies recently few more techniques are also involved to increase the bioavailability of Res which includes, amorphous solid dispersions of eudragit E/Hydrochloric Acid $(\mathrm{HCl})^{[24]}$ using spray drying approach, microspheres of eudragit ${ }^{\circledR}$ retard polymer ${ }^{[25]}$, Gamma $(\gamma)$ cyclodextrin inclusion complexes $^{[26]}$ and Hydroxypropyl-Beta (HP- $\beta$ ) cyclodextrin or $\beta$-cyclodextrin inclusion complexes ${ }^{[27]}$. But the problems associated with these strategies are complex processes, Drug Loading (DL) issues, sometimes stability problems, cost-effective and nonuniformity of the drug:polymer blending process.

In this context, the PNPs are an excellent approach and colloidal carriers for poorly water-soluble antioxidant to conflict these above disadvantages. The process variables along with in vitro physicochemical studies of PNPs influence the in vivo pharmacokinetic parameters as well as antioxidant properties of the Res. Furthermore, PNPs demonstrated a prolonged and sustained release profile of Res which supports to diminishes the toxicity ${ }^{[28]}$. In PNPs preparations, Eudragit $^{\circledR}$ E100 (EE100) copolymer was used to prepare Res encapsulated PNPs and act as colloidal carriers. EE100 copolymer is the 1:2:1 ratio of methyl methacrylate, N,N-dimethylaminoethyl methacrylate and butyl methacrylate monomers has been usually incorporated to increase the solubility of poorly watersoluble antioxidant compound which can be oppressed in many drug delivery systems ${ }^{[29]}$. Particle Size (PS), Zeta Potential (ZP) values and composition of PNPs take part in encapsulation and enhanced the scavenging activity of Res in PNPs $^{[9]}$. Thus, to the best of our knowledge, there is no scientific literature reflect to develop this novel PNPs system to enhance the oral bioavailability and antioxidant potential of the waterinsoluble drug, Res.

Therefore, the principle purpose to achieve high dissolution and oral bioavailability profile, better antioxidant potential and no side effects of Res, oral PNPs is extremely advantageous strategies. The present investigation suggested that the emulsificationdiffusion-evaporation technique was employed to prepare Res-Encapsulated Polymeric Nanoparticles (Res-PNPs). "Taguchi orthogonal array design" was used to check the effect of independent variables on dependent response variables i.e. mean PS and Encapsulation Efficiency (EE). The optimized ResPNPs were analyzed for the physical state as well as in vitro physicochemical studies. The in vitro release study of optimized Res-PNPs was performed up to $48 \mathrm{~h}$. The stability study of optimized Res-PNPs was performed in real-time $\left(25^{\circ} \pm 2 \% 60 \% \pm 5 \%\right.$ Relative Humidity (RH)) for 9 mo as well as at accelerated condition $\left(40^{\circ} \pm 2^{\circ} / 75 \% \pm 5 \% \mathrm{RH}\right)$ for 6 mo. Further, in vivo pharmacokinetic parameters of the optimized Res-PNPs were performed in healthy Charles Foster rats. Furthermore, the optimized Res-PNPs were analyzed to check their ability to scavenge the radical, 2,2'-Azino-bis(3-ethylbenzthiazoline-6-sulfonic acid) diammonium salt $\left(\mathrm{ABTS}^{+}\right)$.

\section{MATERIALS AND METHODS}

\section{Materials:}

Res was provided by Cayman Chemical Company, USA. EE100 and Poloxamer 188 (PLX188) were gifted from Evonik Degussa, Mumbai and Mankind Pharma Ltd., Okhla, India. Chloroform, ethanol and methanol were purchased from SD Fine-Chem Ltd (Mumbai, 
India). Nanofree ${ }^{\mathrm{TM}}$ grade water (Barnstead, Dubuque, IA) was used for all the studies. ABTS and potassium persulfate were obtained from Sigma-Aldrich, USA. All other chemicals used in this study were of analytical grade.

\section{Preparation of Physical Mixture (PM):}

The PM of Res, EE100 and PLX188 was prepared manually using pestle and mortar in a mass ratio of 0.027:4.7:0.85 g. The mixing time was $10 \mathrm{~min}$ followed by sieved through \#40 to obtain a homogeneous mixture and stored in a desiccator till further use.

\section{Preparation of Res-PNPs:}

The emulsification-diffusion-evaporation technique was employed to prepared Res-PNPs with the small modification ${ }^{[30]}$. The independent variables such as drugpolymer ratio, amount of ethyl acetate, homogenization speed and PLX188 concentration were used to prepare Res-PNPs. Briefly, Res and EE100 were dissolved in the organic solvent, ethyl acetate and stirred using a magnetic stirrer (IKA ${ }^{\circledR}, \mathrm{C}-\mathrm{MAG}, \mathrm{HS} 7$, Germany) for $10 \mathrm{~min}$. Then, the prepared organic solution was consequently added drop by drop to $50 \mathrm{ml}$ aqueous PLX188 solution using a syringe at a distance of $\sim 4 \mathrm{~cm}$ above the surface of the external aqueous phase under homogenizer (Dhian Scientific, M30, South Korea) for $10 \mathrm{~min}$. Thereafter, $25 \mathrm{ml}$ of water was added into the final emulsion to allow diffusion of the organic solvent into the water followed by magnetically stirring at room temperature for $24 \mathrm{~h}$ to evaporate the organic solvent and formation of Res-PNPs. Further, the prepared ResPNPs were centrifuged (Refrigerated Centrifuge (RC) $4100 \mathrm{~F}$, Eltech, Mumbai, India) at $15000 \mathrm{rpm}$ for 30 min. The prepared sediment was washed with water and resuspended in water containing $2 \% \mathrm{w} / \mathrm{v}$ mannitol as a cryoprotectant and lyophilized using lyophilizer (Freezone, Labconco, USA). Finally, the lyophilized Res-PNPs were stored in glass vessels till further use.

\section{PS, Polydispersity Index (PDI) and ZP:}

The PS and ZP of Res-PNPs in dispersion were determined using the Delsa ${ }^{\mathrm{TM}}$ Nano $\mathrm{C}$ particle size analyzer (Beckman Coulter, Inc., USA). For PS measurement, dispersions were dispersed in distilled water and put into cuvettes of PS analyzer and measured the PS and PDI of the PNPs. The mean PS was determined from triplicate measurements of each sample. Similarly, samples were placed in a zeta cell and the ZP was measured.

\section{EE and DL:}

EE and DL of Res-PNPs were evaluated by a direct method after $24 \mathrm{~h}$ of preparation using HighPerformance Liquid Chromatography (HPLC). Briefly, $10 \mathrm{mg}$ of Res-PNPs was dissolved in $1 \mathrm{ml}$ of methanol followed by dilution with the mobile phase. The diluted PNPs solution was filtered through a $0.45 \mu \mathrm{m}$ syringe filter (Polyethersulfone (PES) grade, Millipore, Bedford, USA) and injected into the HPLC system for quantification at a wavelength of $306 \mathrm{~nm}$. The Percentage (\%) EE and \% DL of Res-PNPs were calculated according to the following equations:

$\% \mathrm{EE}=$ (Amount of Res encapsulated/Total amount of Res used) $\times 100$

$\% \mathrm{DL}=($ Amount of Res loaded/Total amount of the prepared formulations $) \times 100$

\section{Taguchi $L_{9}$ orthogonal array design:}

A Taguchi $\mathrm{L}_{9}\left(3^{4}\right)$ orthogonal array design factors (independent and dependent) and Analysis of Variance (ANOVA) statistical analysis were adopted by using MINITAB ${ }^{\circledR} 17$ software to decide the optimal conditions related to selected independent factors which should be used to establish an optimized formulation composition of Res-PNPs with minimal PS and high $\%$ EE. The $\mathrm{L}_{9}$, 3-level 4-factors experimental design such as drug:polymer ratio, the amount of ethyl acetate, homogenization speed and PLX188 concentrations. The four independent variables each at three levels (low, medium and high) would give only nine experimental trials as depicted in Table 1. Also, robustness, suitability and reliability of Taguchi orthogonal array design were determined to be prepared and characterizing ResPNPs formulation at an optimized level of independent factors and their dependent responses. The experiments were performed thrice and characterized various parameters $^{[31,32]}$.

\section{Compatibility studies of Res-PNPs:}

Fourier-Transform Infrared (FT-IR) spectroscopy studies: The FT-IR spectra of pure Res, EE100, PM and optimized Res-PNPs were evaluated by FT-IR spectrophotometer (Shimadzu, 8400S, Tokyo, Japan) to monitor any significant change if occurs, between Res and components of Res-PNPs, both after and before the encapsulation of Res. The small quantity of each component was triturated gently with anhydrous Potassium Bromide (KBr) and compressed to form a thin pellet in the FT-IR sample holder. The scanning 
TABLE 1: TAGUCHI ORTHROGONAL ARRAY DESIGN OF EXPERIMENT AND CORRESPONDING PHYSICOCHEMICAL CHARACTERIZATIONS OF DIFFERENT RES-PNPS BATCHES (ALL VALUES ARE REPORTED IN MEAN $\pm S D ; n=3$ )

\begin{tabular}{lccccccccc}
\hline Batches & A & B & C & D & PS $(\mathrm{nm})$ & ZP $(\mathrm{mV})$ & PDI & $\%$ EE & $\%$ DL \\
\hline Res-ENP1 & $01: 04$ & 2.5 & 8000 & 0.5 & $599 \pm 1.35$ & $10.2 \pm 1.17$ & $0.513 \pm 0.071$ & $63.45 \pm 3.93$ & $0.886 \pm 0.082$ \\
Res-ENP2 & $01: 04$ & 5 & 10000 & 1 & $502 \pm 5.41$ & $19.2 \pm 1.73$ & $0.411 \pm 0.052$ & $61.38 \pm 4.12$ & $0.627 \pm 0.047$ \\
Res-ENP3 & $01: 04$ & 7.5 & 12000 & 1.5 & $410 \pm 9.78$ & $38.1 \pm 2.56$ & $0.203 \pm 0.079$ & $66.88 \pm 5.45$ & $0.512 \pm 0.065$ \\
Res-ENP4 & $01: 06$ & 2.5 & 10000 & 1.5 & $762 \pm 6.06$ & $24.7 \pm 3.71$ & $0.401 \pm 0.056$ & $67.65 \pm 7.29$ & $1.134 \pm 0.017$ \\
Res-ENP5 & $01: 06$ & 5 & 12000 & 0.5 & $645 \pm 6.94$ & $17.3 \pm 6.26$ & $0.487 \pm 0.058$ & $75.66 \pm 1.92$ & $0.617 \pm 0.049$ \\
Res-ENP6 & $01: 06$ & 7.5 & 8000 & 1 & $687 \pm 9.87$ & $15.3 \pm 1.98$ & $0.472 \pm 0.057$ & $70.98 \pm 5.16$ & $0.413 \pm 0.013$ \\
Res-ENP7 & $01: 08$ & 2.5 & 12000 & 1 & $578 \pm 9.27$ & $23.8 \pm 6.35$ & $0.341 \pm 0.089$ & $52.47 \pm 2.19$ & $1.244 \pm 0.046$ \\
Res-ENP8 & $01: 08$ & 5 & 8000 & 1.5 & $745 \pm 1.94$ & $28.6 \pm 7.42$ & $0.397 \pm 0.052$ & $69.37 \pm 6.49$ & $0.703 \pm 0.021$ \\
Res-ENP9 & $01: 08$ & 7.5 & 10000 & 0.5 & $619 \pm 7.47$ & $19.7 \pm 1.64$ & $0.822 \pm 0.055$ & $65.22 \pm 3.22$ & $0.412 \pm 0.011$ \\
\hline N
\end{tabular}

Note: Where, A-Drug:polymer ratio; B-Amount of ethyl acetate (ml); C-Homogenization speed (rpm); D-PLX188 concentration (\% w/v); PS-Mean particle size; ZP-Zeta potential; PDI-Polydispersity index; \% EE-Percent entrapment efficiency; \% DL-Percent drug loading

was performed over the wavenumber ranging from $4000-400 \mathrm{~cm}^{-1}$ at room temperature and resolution was set at $4 \mathrm{~cm}^{-1}$.

Differential Scanning Calorimetry (DSC): The physical state of Res inside PNPs and compatibility of Res with each component of PNPs were evaluated by DSC. The thermograms were recorded using DSC Q1000 (TA Instruments, USA) which was previously calibrated with indium. The weighed samples $(2 \mathrm{mg})$ were sealed in aluminum pans and scanned at a heating rate of $10^{\circ} \mathrm{min}^{-1}$ over the temperature range of $30-275^{\circ}$, under a nitrogen atmosphere with a flow rate of $50 \mathrm{ml}$ $\min ^{-1}$.

X-Ray Diffraction Analysis (XRD): X-ray diffraction patterns of pure Res, EE100, PM and optimized ResPNPs were examined using XRD (Bruker D8 Discover) with Nickel (Ni) filtered Copper K Alpha-1 $\left(\mathrm{Cu}-\mathrm{K} \alpha_{1}\right)$ radiation at $45 \mathrm{kV}$ and $40 \mathrm{~mA}$. The scattered radiation in crystalline regions of samples was measured with a vertical goniometer. The diffraction patterns were obtained between $10^{\circ}$ and $50^{\circ}$ angle using a step size of $0.045^{\circ}$ with a detector resolution in $2 \theta$ at $25^{\circ}$.

Transmission Electron Microscopy (TEM) study: The structure and shape of the optimized Res-PNPs were examined by employing High-Resolution Transmission Electron Microscopy (HR-TEM). In short, a drop of appropriately diluted Res-PNPs was placed on the carbon-coated copper grid. After $1 \mathrm{~min}$ of adsorption, excess liquid was wicked off with filter paper and air-dried at room temperature. Then, the grid was examined using HR-TEM (TECHNAI 20G2, FEI Company, Netherlands, Holland) at an accelerating voltage of $200 \mathrm{kV}$ with different magnifications. Moreover, the electron diffraction pattern of optimized Res-PNPs revealed the amorphous diffraction halo inside the matrix of PNPs along with the absence of star shape particles.

Atomic Force Microscopy (AFM) study: The morphology of optimized Res-PNPs was inspected by mounting on AFM scanner (NT-MDT, Moscow, RUSSIA) using Solver next software. A drop of PNPs dispersions $(1 \mathrm{mg} / \mathrm{ml})$ was placed on freshly cleaved mica. Then, after $5 \mathrm{~min}$ of incubation, the surface was gently rinsed with deionized water to remove unbound optimized Res-PNPs. The sample was air-dried at room temperature and mounted on the microscope scanner and captured in noncontact mode with a scanning rate of $0.5 \mathrm{~Hz}$.

In vitro release study: In vitro release of pure Res and optimized Res-PNPs were evaluated using dialysis membrane technique with a cutoff molecular weight of 12 000-14 000 Da. Dialysis bag filled with phosphate buffer, $\mathrm{pH} 7.4$ containing $0.1 \% \mathrm{w} / \mathrm{v}$ of Tween $80^{[33]}$ and optimized Res-PNPs equivalent to $2 \mathrm{mg}$ of Res and placed in $50 \mathrm{ml}$ of release medium stirring at $100 \mathrm{rpm}$ at $37^{\circ}$ using a magnetic stirrer. Aliquots $(1 \mathrm{ml})$ were picked off at predetermined time intervals $(0,0.5,1,2$, $3,4,5,6,8,12,24$ and $48 \mathrm{~h}$ ) and replace with an equal volume of the same fresh medium to maintain sink condition. The quantification of aliquots sample was examined using HPLC at $306 \mathrm{~nm}$ wavelength. Further, the zero-order, first-order, Higuchi and KorsmeyerPeppas model was applied to evaluate the drug release kinetics and mechanism.

Stability study of Res-PNPs: Stability studies were performed to assess the storage stability of optimized Res-PNPs at room temperature $\left(25 \pm 2^{\circ}, 60 \pm 5 \% \mathrm{RH}\right)$ for $9 \mathrm{mo}$ and at accelerated conditions $\left(40 \pm 2^{\circ}, 75 \pm 5 \%\right.$ $\mathrm{RH})$ for 6 mo to check any changes in physicochemical properties such as mean PS, PDI and \% EE. 


\section{In vivo pharmacokinetic study:}

Animals and dosing: The Central Animal Ethical Committee (Committee for the Purpose of Control and Supervision of Experiments on Animals (CPCSEA)) approved the protocol for pharmacokinetic study. Healthy Charles Foster rats of either sex (weighed, $150-200 \mathrm{~g}$ ) were housed in polypropylene cages over dust-free husk for $1 \mathrm{w}$ before the day of experiments with $12 \mathrm{~h}$ light/dark cycle at $25 \pm 2^{\circ}$ and $40-70 \% \mathrm{RH}$. The rats were fed with chow and water ad libitum ${ }^{[34]}$. The animals were divided into three groups, Group I $(n=6)$ and Group II $(\mathrm{n}=6)$ which received pure Res and PM (solubilized in $0.3 \%$ sodium carboxymethylcellulose in purified water), respectively and Group III $(n=6)$ received optimized Res-PNPs (equivalent to 25 $\mathrm{mg} / \mathrm{kg}$ of Res) were given oral route using needle gavages. Blood samples $(200 \mu 1)$ were withdrawn via retro-orbital plexus with predetermined time points $(0,0.25,0.5,0.75,1,2,4,8,12$ and $24 \mathrm{~h})$ and collected in heparinized Eppendorf tubes. Further, plasma was separated out instantaneously centrifugation at $5000 \mathrm{rpm}$ for $10 \mathrm{~min}$ at $-4^{\circ}$ and stored at $-20^{\circ}$ until further analysis.

\section{Chromatography setting and extraction techniques:}

The quantification of Res was assessed by ReversePhase (RP)-HPLC as scientifically reported earlier ${ }^{[35]}$. The HPLC system consists of inline degasser, 515 HPLC binary pump (Waters, USA), rheodyne $7752 \mathrm{i}$ manual injector (Waters, USA), $\mathrm{C}_{18}$ reverse-phase $(250 \times 4.6 \mathrm{~mm}$, $5 \mu \mathrm{m}$ ) Octadecyl-Silica 2 (ODS-2) column protected with a guard column $(12 \times 4.6 \mathrm{~mm}, 5 \mu \mathrm{m})$ (Waters, USA) and a photodiode array detector (Waters, USA). The mobile phase methanol:phosphate buffer, $\mathrm{pH} 6.8(\mathrm{pH}$ adjusted with $0.5 \% \mathrm{v} / \mathrm{v}$ orthophosphoric acid solution in Milli-Q water) with the ratio of $63: 37 \% \mathrm{v} / \mathrm{v}$ along with the flow rate was set at $1.0 \mathrm{ml} / \mathrm{min}$. The column temperature was maintained at $25 \pm 2^{\circ}$ using a column oven (Waters, USA) and effluent was detected at $306 \mathrm{~nm}$. Peak area and retention time were determined by operating software Empower Node 2054. Calibration curves were drawn in the range of $10-5000 \mathrm{ng} / \mathrm{ml}$. The run time was found to be $6.4 \mathrm{~min}$ at a temperature of $25^{\circ}$. The actual Res concentration in plasma samples was estimated from the calibration curve prepared by spiking the known concentration of Res in plasma and analyzed using RP-HPLC.

A liquid-liquid extraction procedure was adopted for the separation of Res from the plasma ${ }^{[36]}$. Plasma with Res and internal standard (Caffeine, $0.436 \mathrm{mg} / \mathrm{ml}$ ) was thawed, $100 \mu \mathrm{l}$ was transferred to $1.5 \mathrm{ml}$ Eppendorf tube and $900 \mu \mathrm{l}$ of mobile phase was added to precipitate plasma proteins. This spiking mixture was vortexed for $5 \mathrm{~min}$ and centrifuged at $5000 \mathrm{rpm}$ for $10 \mathrm{~min}$. The supernatant was transferred to a glass tube and evaporated in a vacuum oven at $40^{\circ}$. The dried residue was reconstituted with $100 \mu 1$ mobile phase and $20 \mu 1$ of samples was filtered through a $0.2 \mu \mathrm{m}$ syringe filter (PES grade, Millipore, Bedford, USA) and injected into RP-HPLC column for quantification of Res ${ }^{[37]}$.

\section{Antioxidant activity:}

The antioxidant activity of pure Res, PM and optimized Res-PNPs were assessed using cation radical $\mathrm{ABTS}^{+}$. A combination of $\mathrm{ABTS}^{+}(7 \mathrm{mM})$ and potassium persulfate $(2.45 \mathrm{mM})$ was primed and permitted to be kept at room temperature ${ }^{[38,39]}$. The $\mathrm{ABTS}^{+}$solution was diluted with $50 \mathrm{mM}$ phosphate buffer, $\mathrm{pH} 7.4$ at an absorbance of $734 \mathrm{~nm}$. For the antioxidant effects of pure Res, PM and optimized Res-PNPs, a different range of concentrations from 1 to $25 \mu \mathrm{M}$ was used. The prepared compounds were incubated at $37^{\circ}$ under continuous agitation and confined from light at $0,24,48$ and $72 \mathrm{~h}$. After incubation at $37^{\circ}$, aliquots with desired concentrations were incubated for 30 min with $\mathrm{ABTS}^{+}$ and absorbance was assessed at $734 \mathrm{~nm}$. The phosphate buffer solution was used as a control for this study.

The percentage of inhibition was calculated by the following equation:

Percentage inhibition $=\left(\mathrm{A}_{\mathrm{c}}-\mathrm{A}_{\mathrm{t}} / \mathrm{A}_{\mathrm{c}}\right) \times 100$

Where $A_{c}$ is the absorbance of control and $A_{t}$ is the absorbance of the test.

The inhibitory concentration of $\mathrm{ABTS}^{+}$at $50 \%$ i.e., Half-Maximal Inhibitory Concentration $\left(\mathrm{IC}_{50}\right)$ was calculated by the linear regression of Res concentration versus percentage of $\mathrm{ABTS}^{+}$inhibition curves.

\section{Statistical evaluation:}

The statistical evaluation (ANOVA) was computed using Graph pad prism software (version 5.03). All the experiments were performed in triplicate and results were expressed as mean \pm Standard Deviation (SD) for in vitro studies and mean \pm Standard Error of the Mean (SEM) for in vivo studies.

\section{RESULTS AND DISCUSSION}

Results of the PS of different Res-PNPs batches were found to be in the range of $410.42 \pm 9.78 \mathrm{~nm}$ (Batch Res-ENP3) to $687.12 \pm 9.87 \mathrm{~nm}$ (Batch Res-ENP6) as 
shown in Table 1. The drug:polymer (concentration of the drug is constant) ratio plays an important role to influence the PS of Res-PNPs. Therefore, raise in the drug:polymer ratio accelerates the construction of bigger size droplet most likely due to enhanced organic phase (ethyl acetate) viscosity, which in due course leads to mired dispersion of organic phase in the aqueous phase which follow-on to enhanced PS after removal of organic phase ${ }^{[40]}$. Further, increased concentration of PLX188 resulted in smaller PS because PLX188 develops boundary layer around PNPs droplets, which prevents impingement of droplets and subsequently formation of non-aggregated polymeric dispersion ${ }^{[41]}$. Furthermore, an increased amount of ethyl acetate resulted in decreased mean PS due to reduced viscosity of organic phase followed by maximum dilution of polymer. Moreover, increased homogenization speed provides shear force to decrease mean PS and viceversa.

PDI values of different Res-PNPs batches were found to be ranging from $0.203 \pm 0.079$ (Batch Res-ENP3) to $0.472 \pm 0.067$ (Batch Res-ENP6) as presented in Table 1. PDI values determine the level of homogeneity $(\mathrm{PDI}<0.25)$ and heterogeneity $(\mathrm{PDI}>0.3)$ of the PNPs. The batch with Res-ENP3 showed a smaller PDI value indicates stable and homogeneous dispersion of PNPs, whereas the batch with Res-ENP6 showed a higher PDI value which favors the destabilization of PNPs due to Ostwald ripening ${ }^{[42]}$. $\mathrm{ZP}$ is the main constraint for determining the physical stability of PNPs. Its high value demonstrated that stable colloidal dispersion followed by PNPs non-aggregation due to repulsion forces between PNPs. The positive or negative ZP values of the PNPs were revealed by electrophoretic mobility measurements. Thus, the prepared Res-PNPs exhibited positive $\mathrm{ZP}$ values due to the presence of polymer terminal carboxylic groups. The $\mathrm{ZP}$ values of prepared Res-PNPs were found to be ranging from $+38.1 \pm 2.56$ (Batch Res-ENP3) to $+10.2 \pm 1.17$ $\mathrm{mV}$ (Batch Res-ENP1) as presented in Table 1 which demonstrated a high electric charge onto the surface of PNPs which resulted in that more stable formulation ${ }^{[43]}$.

Results of the \% EE and \% DL of different batches of Res-PNPs formulations are shown in Table 1. Many independent variables such as drug:polymer ratio, organic phase (internal phase) and aqueous phase (external phase) were tailored to accomplish desirable $\% \mathrm{EE}$ and \% DL of Res-PNPs. During the entrapment process, an aqueous PLX188 solution was used as an external phase to hamper the degradation of Res. The $\%$ $\mathrm{EE}$ values were found to be ranging from $52.47 \pm 2.19 \%$
(Batch Res-ENP7) to 75.66 $\pm 1.92 \%$ (Batch Res-ENP5) whereas, \% DL values ranging from $0.412 \pm 0.011 \%$ (Batch Res-ENP9) to $1.244 \pm 0.046 \%$ (Batch ResENP7) which attributed to excellent drug:polymer affinity ${ }^{[44]}$. At excellent drug:polymer ratio, the viscosity of organic phase (ethyl acetate) enhances which eventually decreases the net shear stress at the time of emulsification which resulted in larger PNPs droplets followed by decreased drug diffusion into external PLX188 phase as resulted that high entrapment of Res. In contrast, a high level of organic-aqueous affinity leads to enhanced stress and interfacial tension of emulsion droplets which resulted in the development of the bigger size of emulsion droplets during the emulsification process which is harsh for organic phase diffusion to external PLX188 solution ${ }^{[45]}$, resulted that excellent \% EE and \% DL. The \% EE and \% DL depends on the Res solubility in the excipients matrix materials (solid polymer or liquid dispersion agent), which is correlated to matrix composition, molecular weight, drug-polymer interactions and presence of functional end groups in either the drug or matrix ${ }^{[46-48]}$. Res comes under small molecules which indicates the use of ionic interaction between drug and polymer matrix materials can be very effective in enhancing $\% \mathrm{EE}$ and $\% \mathrm{DL}^{[49,50]}$.

Taguchi orthogonal array design qualitatively analyzes the correlations between independent variables at diverse levels by scheming an orthogonal table and drawing statistical analysis based on the various process parameters. A Taguchi orthogonal array design at four independent variables and three levels were applied and optimize the best formulation composition ${ }^{[51]}$. The dependent variables considered were mean PS and \% EE. The range of mean PS and \% EE was found to be $410 \pm 9.78$ to $762 \pm 6.06 \mathrm{~nm}$ and $52.47 \pm 2.19$ to 75.66 $\pm 1.92 \%$, respectively. However, based on the results of mean PS and \% EE, it was very difficult to select the optimized formulation composition. Therefore, the mean value of PS $\left(\mathrm{PS}_{\mathrm{i}}\right)$, mean value of $\mathrm{EE}\left(\mathrm{EE}_{\mathrm{i}}\right)$, delta values and corresponding rank of each response that influenced the mean PS are listed in decreasing order as follows $\mathrm{C}>\mathrm{D}>\mathrm{B}>\mathrm{A}$. Moreover, the factor's influences on mean PS at individual levels within each factor are explained by $\mathrm{PS}_{\mathrm{i}}$ and can be ranked as $\mathrm{A}$ : $1>2>3$; $\mathrm{B}$ : $2>1>3$; $: 3>1>2$; D: $3>2>1$. So, the resultant optimum formulation composition should be $\mathrm{A}_{1} \mathrm{~B}_{2} \mathrm{C}_{3} \mathrm{D}_{3}$. Similarly, the factors influencing \% $\mathrm{EE}$ was in the order of $\mathrm{B}>\mathrm{A}>\mathrm{C}>\mathrm{D}$ based on the delta value and the individual levels within each factor are ranked as $\mathrm{A}: 1>2>3$; $\mathrm{B}$ : $3>1>2$; $: 1>3>2$; D: $3>1>2$ as shown in Table 2 . The 
highest $\%$ EE could be observed at $\mathrm{A}_{1} \mathrm{~B}_{3} \mathrm{C}_{1} \mathrm{D}_{3}$, which showed that both responses cannot have their preferred values at the same variable setting. ANOVAresults along with delta value recommended that factors $C$ and $D$ were highly significant for mean PS which is having $\mathrm{p}$ value of 0.012 and 0.005 , respectively at a $95 \%$ confidence interval. Thus, the other two factors can be arbitrarily affecting the response. The $\mathrm{p}$ values of factors $\mathrm{A}$ and $B$ were found to be 0.007 and 0.005 , respectively at a $95 \%$ confidence interval for the highest \% $\mathrm{EE}$ as presented in Table 3. Thus, the level setting $\mathrm{C}_{3} \mathrm{D}_{3}$ and $\mathrm{A}_{1} \mathrm{~B}_{3}$ were significant factors for mean PS and $\%$ EE, respectively. Therefore, mean PS and \% EE was considered to be reasonably the most important response parameters and the established optimized formulation compositions were found to be 1:4 (w/w) Res/EE100 ratio, $7.5 \mathrm{ml}$ ethyl acetate, $12000 \mathrm{rpm}$ homogenization speed and $1.5 \% \mathrm{w} / \mathrm{v}$ PLX188 concentration i.e. batch Res-ENP3.

Results of the FT-IR spectra of pure Res EE100, PM and optimized Res-PNPs (batch Res-ENP3), are shown in fig. 1. Pure Res exhibited its characteristics absorption bands at $3088.7 \mathrm{~cm}^{-1}$ for O-H stretching of the alcoholic group, $1606.7 \mathrm{~cm}^{-1}$ for $\mathrm{C}-\mathrm{C}$ stretching of the olefinic group, $1442.8 \mathrm{~cm}^{-1}$ and $1587.4 \mathrm{~cm}^{-1}$ for $\mathrm{C}=\mathrm{C}$ stretching of the aromatic ring, $1153.4 \mathrm{~cm}^{-1}$ for $\mathrm{C}-\mathrm{O}$ stretching and $964.4 \mathrm{~cm}^{-1}$ for trans olefinic bond [fig. 1(a) $]^{[52]}$. Further, FT-IR spectra of EE100 [fig. 1(b)] demonstrates characteristics absorption bands at $2858 \mathrm{~cm}^{-1}$, which indicate the presence of $-\mathrm{CH}_{2}$ symmetric stretching, at $1728 \mathrm{~cm}^{-1}$ indicates $\mathrm{C}=\mathrm{O}$ carbonyl stretching ${ }^{[31]}$.

TABLE 2: EXPERIMENTAL SIGNAL TO NOISE (S/N) RATIO FOR THE RESPONSE PARAMETERS AT DIFFERENT LEVELS OF PREPARED RES-PNPS ACCORDING TO TAGUCHI ORTHOGONAL ARRAY DESIGN

\begin{tabular}{lcccc}
\hline \multirow{2}{*}{ Levels } & \multicolumn{4}{c}{ Independent factors } \\
\cline { 2 - 5 } & A & B & C & D \\
\hline $\mathrm{PS}_{1}$ & -54.89 & -54.84 & -55.13 & -55.46 \\
$\mathrm{PS}_{2}$ & -54.99 & -55.78 & -53.37 & -54.17 \\
$\mathrm{PS}_{3}$ & -54.98 & -54.73 & -56.22 & -56.11 \\
Delta value & 0.10 & 1.05 & 2.85 & 1.94 \\
Rank & 4 & 3 & 1 & 2 \\
$\mathrm{EE}_{1}$ & -13.45 & -11.12 & -11.46 & -12.01 \\
$\mathrm{EE}_{2}$ & -11.93 & -10.08 & -12.75 & -11.67 \\
$\mathrm{EE}_{3}$ & -10.65 & -13.61 & -12.23 & -12.27 \\
Delta value & 2.8 & 3.53 & 1.29 & 0.6 \\
Rank & 2 & 1 & 3 & 4 \\
\hline
\end{tabular}

Note: $\mathrm{PS}_{i}$ and $\mathrm{EE}_{\mathrm{i}}$ is the mean value of PS and EE. Delta value is the difference between the maximum value and the minimum value of $\mathrm{PS}_{\mathrm{i}}$ and $\mathrm{EE}_{\mathrm{i}}$

TABLE 3: ANOVA TABLE FOR THE RESPONSE PARAMETERS OF PS AND EE

\begin{tabular}{|c|c|c|c|c|c|c|}
\hline Factors & DoF & SS & MS & $\% \mathrm{PC}$ & $\mathrm{F}^{\mathrm{a}}$ & $\mathrm{Pb}^{\mathrm{b}}$ \\
\hline \multicolumn{7}{|l|}{ PS } \\
\hline$A$ & (2) & (14.8245) & (7.4123) & 58.2925 & Pooled & \\
\hline B & $(2)$ & (1.2359) & $(0.6179)$ & 4.8597 & Pooled & \\
\hline C & 2 & 9.2459 & 4.6229 & 36.3565 & 1.151 & 0.012 \\
\hline D & 2 & 0.1249 & 0.0625 & 0.4911 & 0.015 & 0.005 \\
\hline Pooled error & (4) & $(16.0604)$ & $(4.0151)$ & & & \\
\hline $\mathrm{SS}_{\text {Total }}$ & 8 & 25.4312 & & 100 & & \\
\hline \multicolumn{7}{|l|}{$\% \mathrm{EE}$} \\
\hline A & 2 & 1.4378 & 0.7189 & 1.8747 & 0.043 & 0.007 \\
\hline B & 2 & 7.6892 & 3.8446 & 10.0260 & 0.227 & 0.005 \\
\hline C & (2) & (14.2196) & (7.1098) & 18.5410 & Pooled & \\
\hline D & (2) & (53.3459) & $(26.6729)$ & 69.5581 & Pooled & \\
\hline Pooled error & (4) & $(67.5655)$ & $(16.8913)$ & & & \\
\hline $\mathrm{SS}_{\text {Total }}$ & 8 & 76.6925 & & 100 & & \\
\hline
\end{tabular}


Therefore, all major peaks of Res and EE100 were observed in FT-IR spectra of PM, as illustrated in fig. 1(c). The optimized Res-PNPs exhibited all the characteristics of absorption peaks of Res with minor shifts in absorption bands as depicted in fig. 1(d). In optimized Res-PNPs, the peak at $3,088 \mathrm{~cm}^{-1}$ becomes wider which exhibits hydrogen bonding in increased or enhanced. The $\mathrm{C}-\mathrm{C}$ stretching of the olefinic group at $1635.6 \mathrm{~cm}^{-1}, \mathrm{C}=\mathrm{C}$ stretching of the aromatic ring at $1464.02 \mathrm{~cm}^{-1}, \mathrm{C}-\mathrm{O}$ stretching at $1147.68 \mathrm{~cm}^{-1}$ and trans olefinic band at $966.37 \mathrm{~cm}^{-1}$ was observed. The existence of all characteristics absorption bands of Res in the optimized Res-PNPs proved that there is the absence of chemical interaction between Res and other formulation excipients.

Results of the DSC thermograms of pure Res, EE100, PM and optimized Res-PNPs are shown in fig. 2. Pure Res exhibited a melting temperature of Res followed by

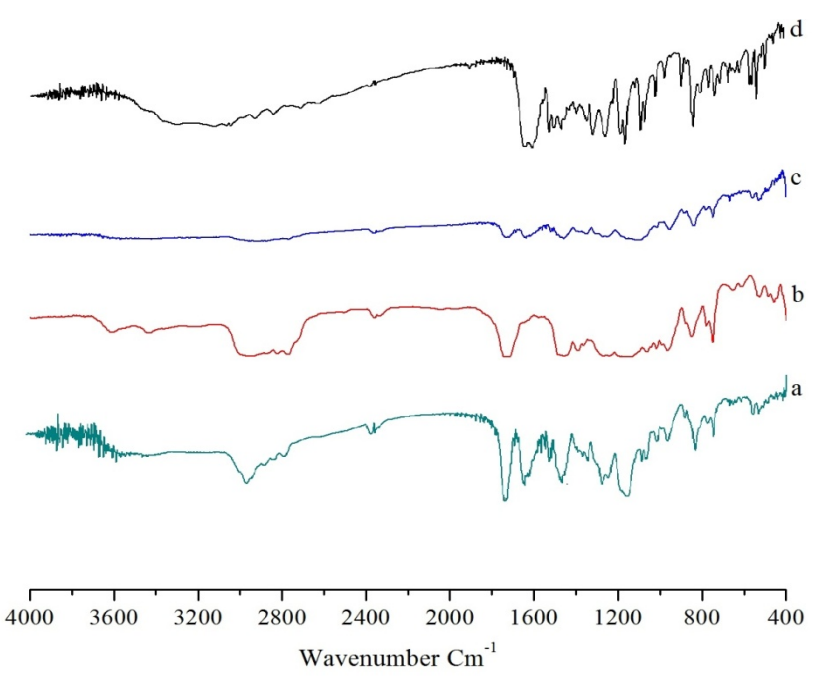

Fig. 1: FT-IR spectra of (a) Pure Res; (b) EE100; (c) PM and (d) Optimized Res-PNPs

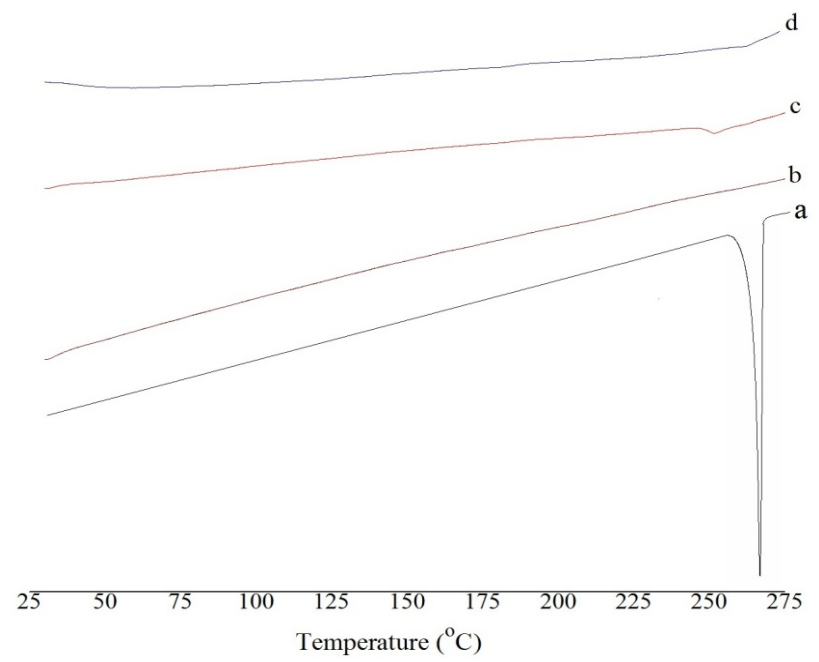

Fig. 2: DSC thermograms of (a) Pure Res; (b) EE100; (c) PM and (d) Optimized Res-PNPs a sharp endothermic decomposition peak at $267.71^{\circ[53]}$. However, this melting peak was absent in the thermogram of optimized Res-PNPs. It was proved that Res was entrapped inside the PNPs as an amorphous form $^{[54]}$.

Results of the Powder X-ray Diffraction (pXRD) study confirm the absence of drug crystallinity. pXRD analysis of pure Res, EE100, PM and optimized Res-PNPs are shown in fig. 3. Pure Res exhibited crystalline nature and sharp diffraction peaks at $6.62^{\circ}, 13.2^{\circ}, 16.36^{\circ}$, $19.18^{\circ}, 22.28^{\circ}, 23.54^{\circ}, 25.18^{\circ}, 28.26^{\circ}, 31.6^{\circ}, 38.32^{\circ}$ and $45.18^{\circ}$ in $2 \theta$ scale as depicted in fig. 3(a) ${ }^{[55]}$. The EE100 does not exhibit any characteristic peaks at $2 \theta$ angles as shown in fig. 3(b). In the case of PM, none of the peaks disappeared which is shown in fig. 3(c). Since EE100 showed the absence of characteristic peak but diffraction peak must be developed from the crystalline form of Res. These results demonstrated that Res was partially present in crystalline form in the PM. Further, the melting of EE100 in PM formulation dissolved some of Res resulted in that partial transformation into an amorphous form. In contrast, optimized ResPNPs exhibited no other characteristics sharp peaks as depicted in fig. 3(d). The above results recommended the absence of crystallinity and the presence of amorphous nature in the PNPs matrix of Res-ENP3. Additionally, XRD results associated with DSC results proved that the transformation of Res from crystalline state to amorphous form ${ }^{[54]}$.

Results of the HR-TEM micrographs assessed the surface morphology of the optimized Res-PNPs. Fig. 4a depicted the development of spherical, smooth and more or less uniform size distribution followed by a low PDI (Table 1) of optimized Res-PNPs. Further,

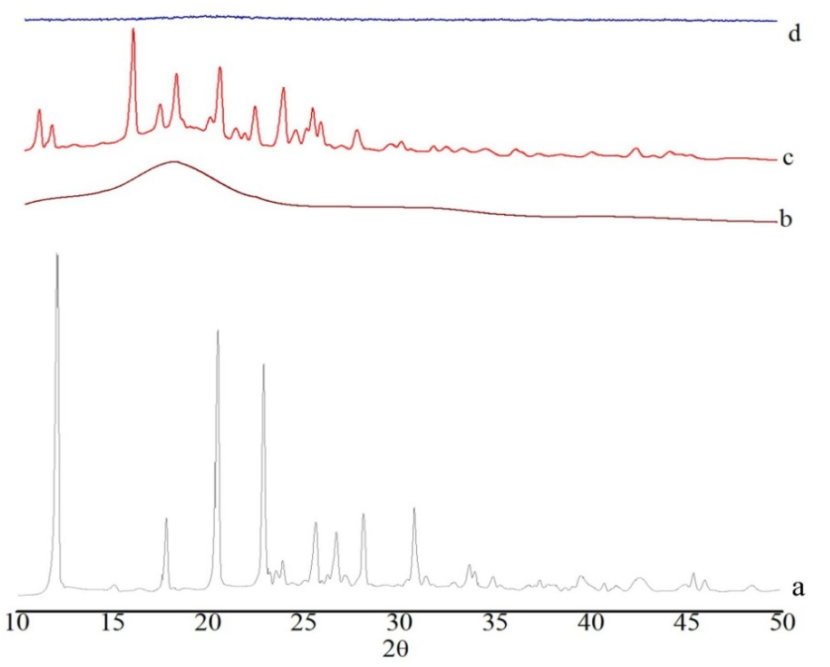

Fig. 3: pXRD curves of (a) Pure Res; (b) EE100; (c) PM and (d) Optimized Res-PNPs 
fig. 4b illustrated the electron diffraction of optimized Res-PNPs which revealed the amorphous halo pattern. These micrographs reveal the absence of star-shaped particles in ring patterns and homogeneous drug distribution inside the matrix of $\mathrm{PNPs}^{[56,57]}$.

Results of the AFM micrographs exhibited wellseparated spherical shapes along with smooth surfaces of optimized Res-PNPs as depicted in fig. 4c (Three Dimensional (3D) image). Further, the micrographs also showed that almost uniform size distribution with a low PDI, which has an average diameter smaller than $410 \mathrm{~nm}$ as examined by the PS analyzer as illustrated in fig. $4 \mathrm{~d}$.

Results of the in vitro release study of pure Res and optimized Res-PNPs in Phosphate-Buffered Saline (PBS, pH 7.4 as depicted in fig. 5. The result recommended that pure Res remained undissolved in PBS, pH 7.4 whereas, optimized Res-PNPs gave $>25$ $\%$ release in the first $2 \mathrm{~h}$ followed by $>75 \%$ release at the end of $48 \mathrm{~h}$ due to the amorphous nature of Res and structural homogeneity in the PNPs matrix which assist higher solubility in PBS. However, the burst effect was showed during the first 30 min (being more than $15 \%$ ) because of immediate release of the surface-bound drug then the mechanism of hydration, polymer swelling or polymer erosion takes place which leads to diffusionbased sustained release of the drug. The presence of EE100 polymer along with surfactant (PLX188) leads to smaller PNPs which renders a massive surface area to volume ratio and facilitating greater interaction between PNPs and gut absorption site, which eventually results in a significant enhancement in the absorption of an incorporated drug. Additionally, smaller PNPs not only defend the drug from the gastrointestinal milieu but also evade the first-pass metabolism by lymphatic uptake via Microfold (M) cells of Peyer's patches and thus diminish the dose and related toxicity. The hydration of polymer brings about extension in diffusional path length of drug which subsequently lowers their diffusion rate ${ }^{[58]}$. Therefore, the relative hydration rate and integrity of the hydrated polymer matrix is the prime mechanism that maintains and facilitates the sustained release profile of PNPs. Thus, the above results suggested that the sustained release of PNPs was governed by the amalgamation of drug diffusion and polymer chain relaxation during polymer swelling ${ }^{[59]}$.

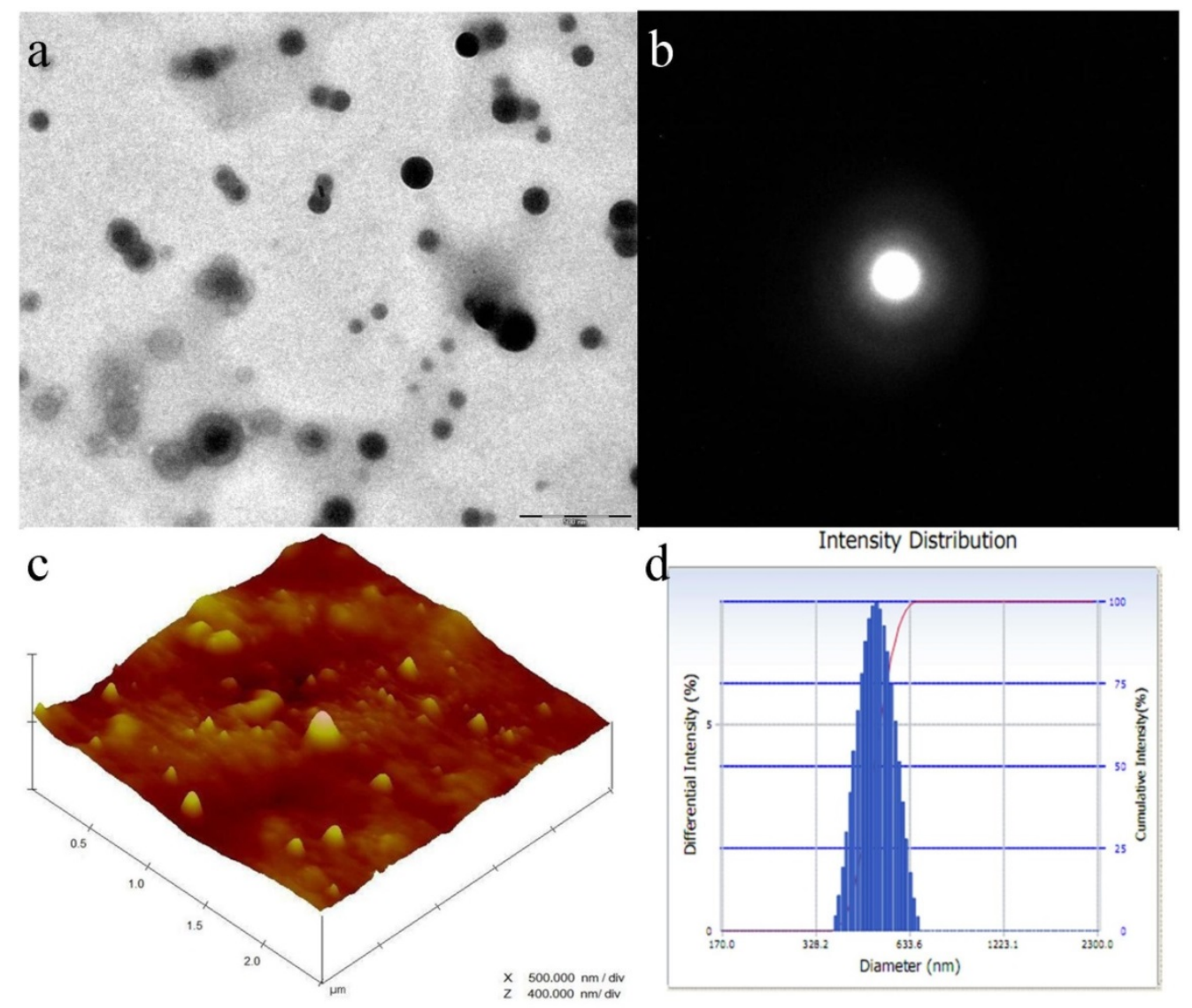

Fig. 4: (a) HR-TEM at $20000 \times$ magnification (bar=500 $\mu \mathrm{m})$; (b) Exhibits electron diffraction pattern of optimized Res-PNPs; (c) Surface morphology of optimized Res-PNPs measured by AFM (3D image) and (d) Mean PS of optimized Res-PNPs measured by PS analyzer (average diameter $=410 \pm 9.78 \mathrm{~nm}, \mathrm{n}=3$ ) 
The rate and extent of Res release might be directly related to the distribution coefficient of Res. Therefore, in vitro release data of Res from PNPs were fitted into several release kinetic equations such as zero order, first order, Higuchi, Hixon-crowel and Korsmeyer-

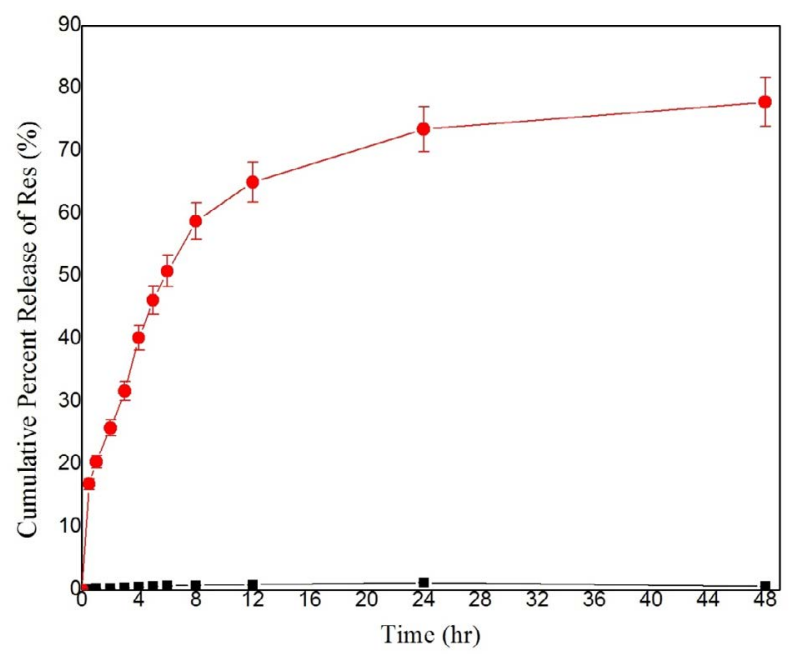

Fig. 5: In vitro release profile of pure Res and optimized ResPNPs in PBS, pH 7.4 for $48 \mathrm{~h}$ (vertical bars represent mean \pm SD, n=3), (ロ) Free Res; () Optimized Res-PNPs
Peppas model. The Higuchi equation was the best fit because of higher correlation coefficient $\left(\mathrm{R}^{2}=0.999\right)$ compared with other kinetic equations which having lower correlation coefficient as presented in Table 4. Further, revealed the release mechanism, KorsmeyerPeppas model was the best fit with $n$ value of 0.476 which indicated Fickian-diffusion mechanism of drug release from PNPs matrix (Table 4) ${ }^{[60,61]}$.

The optimized Res-PNPs were stable at room temperature for $9 \mathrm{mo}$ and accelerated condition for 6 mo for all in vitro physicochemical parameters. There are no significant changes observed throughout the stability periods which indicated that the optimized Res-PNPs were highly stable as depicted in fig. $6 \mathrm{a}$ and fig. $6 \mathrm{~b}$, respectively.

Fig. 7 illustrated the plasma concentration-time curve obtained after oral administration of pure Res suspension, PM and optimized Res-PNPs. The Area under the Curve (AUC) $)_{0-24}$ and Maximum Plasma Concentration $\left(\mathrm{C}_{\max }\right)$ were found to be 1.98-fold, 1.57fold as well as 4.07-fold, 5.03-fold greater when Res

TABLE 4: RELEASE PARAMETERS FOR OPTIMIZED RES-PNPS (BATCH RES-ENP3) OBTAINED AFTER FITTING IN VITRO RELEASE DATA TO FIVE DIFFERENT KINETIC MODELS

\begin{tabular}{lccccc}
\hline Batch & Zero order & First order & Higuchi model & Hixon-Crowel model & Korsemeyer-Peppas model \\
\hline \multirow{2}{*}{ Res-ENP3 } & $\mathrm{K}_{\mathrm{z}}=1.987$ & $\mathrm{~K}_{\mathrm{F}}=0.112$ & $\mathrm{~K}_{\mathrm{H}}=19.53$ & $\mathrm{~K}_{\mathrm{HC}}=0.101$ & $\mathrm{~K}_{\mathrm{p}}=0.367$ \\
& (Concentration/time) & $\left(\right.$ time $\left.^{-1}\right)$ & $\mathrm{R}^{2}=0.999$ & $\mathrm{R}^{2}=0.899$ & $\mathrm{R}^{2}=0.977$ \\
& $\mathrm{R}^{2}=0.735$ & $\mathrm{R}^{2}=0.705$ & & & $\mathrm{n}=0.476$ \\
\hline
\end{tabular}

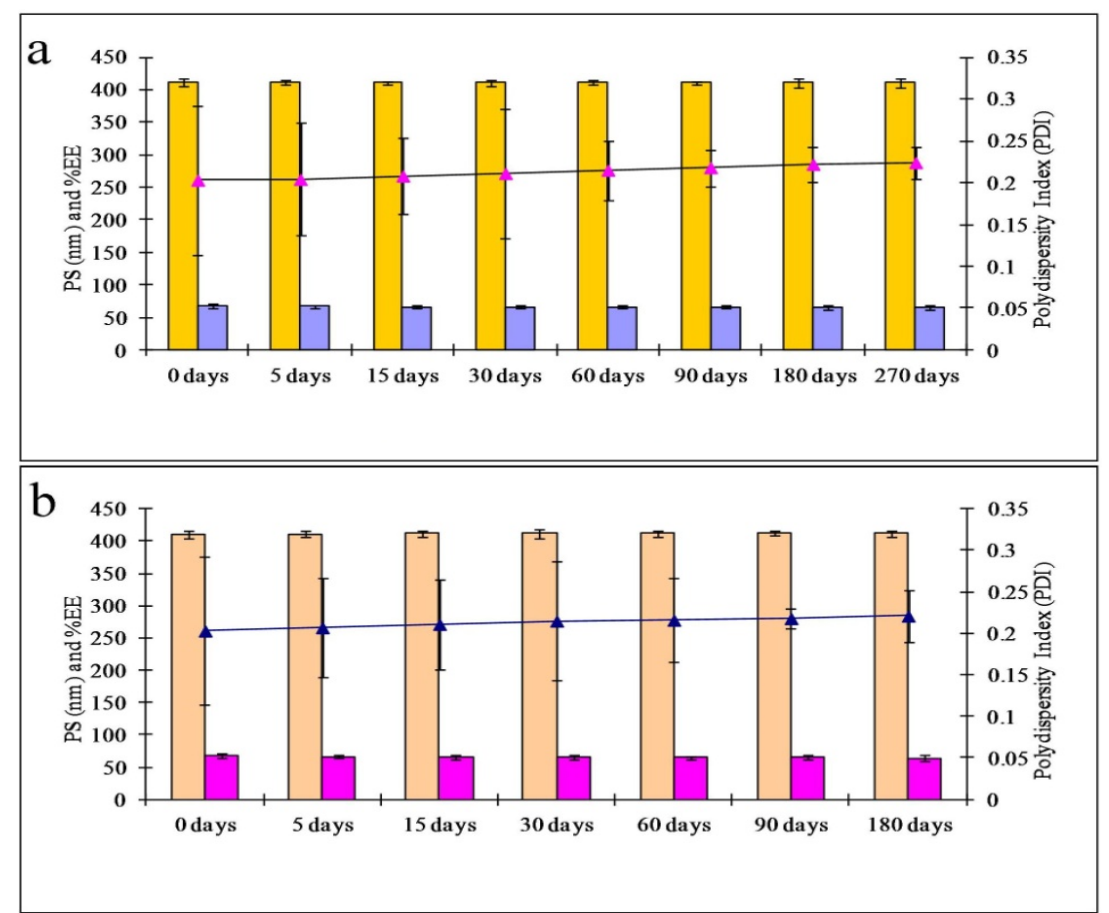

Fig. 6: Stability study data of the optimized Res-PNPs during storage, (a) At room temperature (25 $\pm 2 \% 60 \% \pm 5 \%$ RH) for 9 mo, ( $\quad$ ) PS (nm); ( $\square$ ) EE; ( $\triangle$ ) PDI; (b) At accelerated condition (40 $\pm 2 \% / 75 \% \pm 5 \%$ RH) for 6 mo (all data were performed in triplicate and the vertical bars represent mean \pm SD, n=3) ( $\square$ PS (nm); ( $\square$ ) \% EE; (A) PDI 


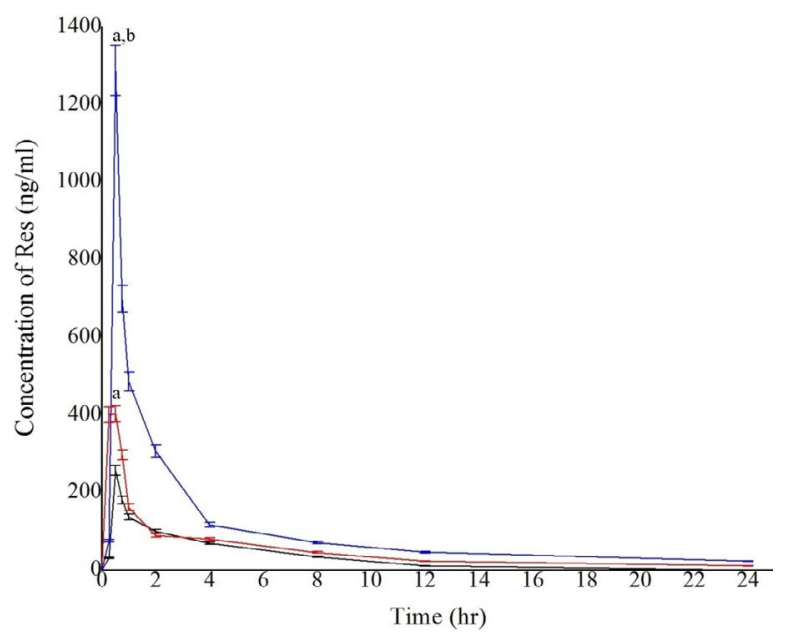

Fig. 7: Plasma concentration-time profile after oral administration of pure Res, PM and optimized Res-PNPs (dose $25 \mathrm{mg} / \mathrm{kg}$ in each group) vertical bars represent mean $\pm \mathrm{SEM} ; \mathrm{n}=\mathbf{6}$, ${ }^{\mathrm{a}} \mathbf{p}<0.05$, compared to the control (pure Res), ${ }^{\mathrm{b}} \mathbf{p}<0.05$, compared to PM, (One-way ANOVA; Tukey's multiple comparison test), ( $\longrightarrow$ ) free Res; (-) PM; ( $\longrightarrow$ ) Optimized ReS-PNPs

was administered as PM and optimized Res-PNPs, respectively when compared with pure Res aqueous suspension. It was observed that plasma levels declined stridently after $2 \mathrm{~h}$ which indicated that rapid systemic elimination and also proved by the short biological halflife of pure Res as presented in Table 5. These results thus recommended significantly $(\mathrm{p}<0.05)$ enhancement in oral bioavailability of Res in case of PM as well as optimized Res-PNPs; though, improvement of oral bioavailability of optimized Res-PNPs was significantly $(\mathrm{p}<0.05)$ higher than that of PM as well as pure Res.

The plasma level of Res after oral administration of pure Res was detected only up to $24 \mathrm{~h}$ with a $\mathrm{C}_{\max }$ value of $256.004 \pm 12.80 \mathrm{ng} / \mathrm{ml}$. The $\mathrm{C}_{\max }$ and $\mathrm{AUC}_{0-24}$ of the drug were increased to $401.765 \pm 20.088 \mathrm{ng} / \mathrm{ml}$ and $1286.635 \pm 64.332(\mathrm{ng} / \mathrm{ml}) \cdot \mathrm{h}$, respectively when PM was administered with the same dose. Further, the orally administered optimized Res-PNPs drastically enhanced the drug-plasma concentration (fig. 7). The $\mathrm{AUC}_{0-24}$ value of optimized Res-PNPs was significantly increased to $3056.458 \pm 128.248$ (ng/ml).h (Table 5). The above results recommended that PM and optimized Res-PNPs significantly increased the oral bioavailability of Res; though, the enhancement of bioavailability with optimized Res-PNPs was significantly $(\mathrm{p}<0.05)$ higher compared with PM. Therefore, M-cells are thought to be comparatively less protected by mucus secretions and drug efflux transporters like P-glycoprotein and are a common delivery for PNPs. However, PNPs adhere and become coated in mucus may have restricted access to M-cells. This mechanism might be due to small PS, increase surface area, reduced diffusion layer thickness, favorable $\mathrm{ZP}$, shape and hydrophobic surface of PNPs play a crucial task in the uptake across the Gastrointestinal (GI) membrane and were found to significantly amend the absorption profile. Furthermore, the enhanced oral bioavailability of Res may also be attributed to amorphous nature of drug inside the PNPs matrices ${ }^{[62]}$ i.e. the original crystalline structure of the drug was absent in the PNPs; supersaturated condition of Res in the intestinal lumen by the use of pH-dependent carrier ${ }^{[63]}$, means they may slow down nucleation or crystal growth by adsorption on the crystal interface, thereby overcrowding crystal growth and the supersaturated solution will be obtained. The concentration increasing mechanism can significantly enhance Res bioavailability; the good adhesion and site-specific of Res-PNPs to gastrointestinal mucosa due to EE100 polymer ${ }^{[62]}$. Moreover, the reason for the enhancement of AUC after oral administration would be due to the sustained action of PNPs inside the blood circulation. Further, the cationic nature of polymer also imparts the mucoadhesive property in the gastrointestinal membrane and permits absorption of PNPs for a longer period and thereby, allows availability of the drug in the systemic circulation for a longer period. This phenomenon can be easily identified in the comparative results of the Mean Residence Time (MRT) of the different studied formulations (pure Res, PM and optimized Res-PNPs). All of these phenomena might be the reason for the increased efficacy as compared to pure Res and PM. Furthermore, not only a small percentage of PNPs can be absorbed from the GI tract. Many types of research are in the area of oral bioavailability enhancement have claimed that a larger portion of the PNPs absorbed in the GIT and thereby, improve the oral bioavailability ${ }^{[64]}$.

The PNPs containing Res were assessed to scavenge the $\mathrm{ABTS}^{+}$radical. The results of radical percentage inhibition gained from $1,5,10,20$ and $25 \mu \mathrm{M}$ pure Res, PM and optimized Res-PNPs were examined at different time intervals $0,24,48$ and $72 \mathrm{~h}$ as showed in Table 6.

At $0 \mathrm{~h}$ time point, it can be observed that the optimized Res-PNPs reveal the non-significant $(\mathrm{p}>0.05)$ similar scavenging activity of $\mathrm{ABTS}^{+}$at entire concentrations. The pure Res demonstrated a significantly $(p<0.05)$ higher percentage of $\mathrm{ABTS}^{+}$inhibition compared with PM and optimized Res-PNPs. At the $24 \mathrm{~h}$ time point, both PM and optimized Res-PNPs exhibited similar inhibition as mentioned in the previous time point except optimized Res-PNPs exhibited significantly 
TABLE 5: IN VIVO PHARMACOKINETIC DATA AFTER ORAL ADMINISTRATION OF PM AND OPTIMIZED RES-PNPS TO RATS, COMPARED WITH PURE RES AQUEOUS SUSPENSION (ALL VALUES REPORTED ARE MEAN $\pm S E M ; n=6$ )

\begin{tabular}{lccc}
\hline Parameters & $\begin{array}{c}\text { Pure Res } \\
\text { (Control) }\end{array}$ & PM & $\begin{array}{c}\text { Optimized } \\
\text { Res-PNPs }\end{array}$ \\
\hline $\mathrm{C}_{\text {max }}(\mathrm{ng} / \mathrm{ml})$ & $256.004 \pm 12.80$ & $401.765 \pm 20.088$ & $1286.635 \pm 64.332$ \\
$\mathrm{~T}_{\max }(\mathrm{h})$ & $0.5 \pm 0.0$ & $0.5 \pm 0.0$ & $0.5 \pm 0.0$ \\
$\mathrm{AUC}_{0-24}(\mathrm{ng} / \mathrm{ml}) . \mathrm{h}$ & $750.268 \pm 1.167$ & $1488.965 \pm 48.378$ & $3056.458 \pm 128.248$ \\
$\mathrm{AUMC}_{0-24}(\mathrm{ng} / \mathrm{ml}) . \mathrm{h}^{2}$ & $920.888 \pm 55.112$ & $3417.395 \pm 174.219$ & $22916.599 \pm 329.769$ \\
$\mathrm{t}_{1 / 2}(\mathrm{~h})$ & $0.623 \pm 0.022$ & $2.431 \pm 0.0752$ & $5.598 \pm 0.198$ \\
MRT $(\mathrm{h})$ & $1.227 \pm 0.112$ & $2.295 \pm 0.076$ & $7.497 \pm 0.261$ \\
\hline
\end{tabular}

Note: $C_{\max }$-Maximum plasma concentration; $T_{\max }$-Time to reach maximum plasma concentration; AUC-Area under the plasma drug concentration-time curve; AUMC-Area under the first-moment plasma drug concentration-time curve; $t_{1 / 2}$-Half-life, MRT-Mean residence time

TABLE 6: PERCENTAGE INHIBITION OF RADICAL ABTS+ OF PURE RES, PM AND OPTIMIZED RES-PNP AT DIFFERENT CONCENTRATIONS (1, 5, 10, 20 AND $25 \mu \mathrm{M})$ AND TIME POINTS (0, 24, 48 AND 72 h), RESPECTIVELY

\begin{tabular}{lccc}
\hline Res concentration $(\mu M)$ & \multicolumn{3}{c}{ Inhibition of ABTS ${ }^{+}(\%)$} \\
\cline { 2 - 4 } 1 & Pure Res & PM & Optimized Res-PNPs \\
\hline 5 & $12.96 \pm 1.18^{\mathrm{b}}$ & $5.86 \pm 1.01^{\mathrm{a}}$ & $9.43 \pm 1.61^{\mathrm{a}}$ \\
10 & $44.25 \pm 2.43^{\mathrm{b}}$ & $30.56 \pm 8.34^{\mathrm{a}, \mathrm{b}}$ & $16.52 \pm 0.43^{\mathrm{a}}$ \\
20 & $66.78 \pm 1.68^{\mathrm{b}}$ & $36.87 \pm 6.86^{\mathrm{a}}$ & $34.58 \pm 1.68^{\mathrm{a}}$ \\
25 & $93.57 \pm 3.89^{\mathrm{b}}$ & $52.75 \pm 4.26^{\mathrm{a}}$ & $57.89 \pm 2.66^{\mathrm{a}}$ \\
$24 \mathrm{~h}$ & $99.96 \pm 0.11^{\mathrm{b}}$ & $66.01 \pm 6.91^{\mathrm{a}}$ & $63.19 \pm 4.14^{\mathrm{a}}$ \\
1 & & & \\
5 & $8.23 \pm 2.81^{\mathrm{a}}$ & $4.95 \pm 0.94^{\mathrm{a}}$ & $3.34 \pm 2.55^{\mathrm{a}}$ \\
& $29.27 \pm 3.57^{\mathrm{b}}$ & $11.27 \pm 4.27^{\mathrm{a}}$ & $15.25 \pm 2.08^{\mathrm{a}}$ \\
& & & \\
20 & $48.28 \pm 5.68^{\mathrm{b}}$ & $21.67 \pm 1.68^{\mathrm{a}}$ & $24.85 \pm 1.86^{\mathrm{a}}$ \\
25 & & & \\
$48 \mathrm{~h}$ & $95.75 \pm 6.98^{\mathrm{b}}$ & $50.57 \pm 4.62^{\mathrm{a}}$ & $75.88 \pm 3.67^{\mathrm{a}}$ \\
1 & $98.11 \pm 1.21^{\mathrm{c}}$ & $66.69 \pm 4.19^{\mathrm{a}}$ & \\
5 & & & $8.51 \pm 5.41^{\mathrm{b}}$ \\
10 & $2.96 \pm 1.62^{\mathrm{c}}$ & $2.68 \pm 0.92^{\mathrm{a}, \mathrm{c}}$ & $22.26^{\mathrm{b}}$ \\
20 & $24.52 \pm 3.28^{\mathrm{a}}$ & $8.62 \pm 1.39^{\mathrm{a}}$ & $36.63 \pm 4.23^{\mathrm{b}}$ \\
25 & $47.88 \pm 4.08^{\mathrm{c}}$ & $19.82 \pm 1.55^{\mathrm{a}}$ & $63.57 \pm 5.69^{\mathrm{b}}$ \\
$72 \mathrm{~h}$ & $89.28 \pm 5.19^{\mathrm{c}}$ & $44.29 \pm 6.23^{\mathrm{a}}$ & $88.28 \pm 5.49^{\mathrm{a}, \mathrm{b}}$ \\
1 & $98.06 \pm 0.82^{\mathrm{b}}$ & $68.38 \pm 5.49^{\mathrm{a}}$ & \\
5 & & & $15.59 \pm 2.49^{\mathrm{a}}$ \\
10 & & $11.68 \pm 1.91^{\mathrm{a}}$ & $26.89 \pm 1.43^{\mathrm{b}}$ \\
25 & $3.69 \pm 0.58^{\mathrm{b}}$ & $13.26 \pm 4.49^{\mathrm{a}}$ & $41.85 \pm 4.97^{\mathrm{b}}$ \\
\hline & $29.56 \pm 3.22^{\mathrm{b}}$ & $25.78 \pm 3.19^{\mathrm{a}}$ & $93.99 \pm 6.81^{\mathrm{b}}$ \\
& $52.88 \pm 3.49^{\mathrm{c}}$ & $56.11 \pm 5.69^{\mathrm{a}}$ & $76.22 \pm 4.33^{\mathrm{a}}$ \\
\hline
\end{tabular}

Note: ${ }^{a, b, c}$ Mean of triplicate $\pm S D$ analyzed per line. Same letters mean statistical equality and inequality stats are indicated for different letters (ANOVA with Tukey's post-test and $p<0.05$ )

$(\mathrm{p}<0.05)$ and enhance $\mathrm{ABTS}^{+}$scavenging activity at a higher concentration, $25 \mu \mathrm{M}$. The pure Res significantly $(\mathrm{p}<0.05)$ decreased the $\mathrm{ABTS}^{+}$scavenging activity at three lower concentrations $(1,5$ and $10 \mu \mathrm{M})$ but at higher concentrations (20 and $25 \mu \mathrm{M})$ insignificantly $(p>0.05)$ same percentage radical inhibition as previous time point. At the $48 \mathrm{~h}$ time point, optimized Res-PNPs demonstrated significantly $(\mathrm{p}<0.05)$ increasing the radical inhibition, while PM exhibited the same profile at the $24 \mathrm{~h}$ time point. At higher concentration $25 \mu \mathrm{M}$, the optimized Res-PNPs exhibit insignificant $(\mathrm{p}>0.05)$ same activity but it was as effective as pure Res. At $72 \mathrm{~h}$ time point, optimized Res-PNPs demonstrated insignificant $(\mathrm{p}>0.05)$ similar scavenging activity as 


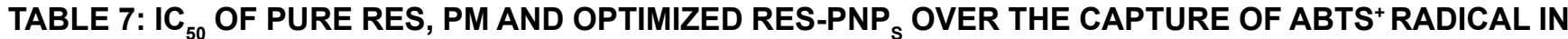
SODIUM PHOSPHATE BUFFER (50 mM, pH 7.4) AND IN THE ABSENCE OF LIGHT AT ROOM TEMPERATURE $(\lambda=734 \mathrm{~nm})$

\begin{tabular}{lccc}
\hline Time $(\mathrm{h})$ & \multicolumn{3}{c}{$\mathrm{IC}_{50}$} \\
\cline { 2 - 4 } & Pure Res $\pm \mathrm{RSD}^{*}$ & PM $^{*} \mathrm{RSD}^{*}$ & Optimized Res-PNPs $\pm R S D^{*}$ \\
\hline 0 & $9.12 \pm 0.18^{\mathrm{b}}$ & $16.68 \pm 0.81^{\mathrm{a}}$ & $19.43 \pm 0.61^{\mathrm{a}}$ \\
24 & $11.35 \pm 0.23^{\mathrm{c}}$ & $20.65 \pm 1.34^{\mathrm{a}}$ & $17.25 \pm 0.88^{\mathrm{b}}$ \\
48 & $12.21 \pm 0.68^{\mathrm{b}}$ & $20.87 \pm 1.76^{\mathrm{a}}$ & $14.88 \pm 0.08^{\mathrm{b}}$ \\
72 & $11.89 \pm 0.89^{\mathrm{b}}$ & $15.57 \pm 1.26^{\mathrm{a}}$ & $13.22 \pm 0.61^{\mathrm{b}}$ \\
\hline
\end{tabular}

Note: a,b,c Mean of triplicate \pm SD analyzed per line. Same letters mean statistical equality and inequality stats are indicated for different letters (ANOVA with Tukey's post-test and $\mathrm{p}<0.05$ ); RSD-Relative Standard Deviation

pure Res but the response gained from optimized ResPNPs was significantly $(\mathrm{p}<0.05)$ inferior. In contrast, we can establish that two higher concentrations ( 20 and $25 \mu \mathrm{M})$ exhibited excellent scavenging activity for pure Res and optimized Res-PNPs. The scavenging activity profile with PM exhibited almost no enhancement in response at $24 \mathrm{~h}$ time point. Conclusively, the profile observed with optimized Res-PNPs demonstrated that excellent scavenging activity and increases with time ${ }^{[65-68]}$.

The $\mathrm{IC}_{50}$ results of Res scavenging $\mathrm{ABTS}^{+}$as a function of time are presented in Table 7 . The $\mathrm{IC}_{50}$ values of pure Res increase with time but optimized Res-PNPs demonstrated minor variations with time and show significant $(\mathrm{p}<0.05)$ superiority with pure Res. The $\mathrm{IC}_{50}$ values of optimized Res-PNPs decreased with time and after 48 and $72 \mathrm{~h}$ time points were considered insignificant ( $p>0.05)$ similar to pure Res.

In conclusion, the current investigation provides a profound insight into the attractive characteristics of oral Res-PNPs as an admirable hydrophobic antioxidant drug. The emulsification-diffusion-evaporation technique was effectively adopted for entrapment of Res molecules inside the PNPs and optimization was performed using the "Quality by design" approach. The Taguchi-orthogonal array design provided a high delta value followed by their rank and significant $(p<0.05)$ ANOVA results. The optimization results recommended that physicochemical properties of Res-PNPs effectively been controlled by independent variables. The optimized PNPs demonstrated nanosized and monodispersed with no agglomeration between each other. The optimized Res-PNPs exhibited sympathetic mean PS, PDI, ZP, \% EE, \% DL and sustained release patterns followed by Fickian diffusion mechanism of drug release from PNPs matrix. The solid-state and morphological evaluation demonstrated the smooth and spherical architecture of PNPs, in which Res molecules were present in an amorphous form inside the PNPs matrix without any physical and chemical interactions. The optimized Res-PNPs were stable at room temperature and accelerated conditions. In vivo pharmacokinetics studies exposed that optimized Res-PNPs exhibited significantly $(p<0.05)$ higher oral bioavailability as compared with pure Res suspension and PM. The optimized Res-PNPs were significantly $(p<0.05)$ very effective as a scavenger of $\mathrm{ABTS}^{+}$radical which suggested that PNPs could be used for antioxidant molecules for the applications in prophylaxis or the treatment of several diseases including oxidative stress. Conclusively, the development of the PNPs approach can be an effective and safe vehicle for antioxidant, Res delivery in numerous therapies. The current research encourages and supports the feat of thorough preclinical studies with Res-encapsulated EE100 nanoparticles as a prerequisite for potentially advancing into human (clinical) applications.

PNPs embrace a clinical significance as a delivery stage for poorly soluble drugs and due to this reason, the recent formulation approach provides an efficient drug carrier. This carrier system can enhance the efficiency of translation from the lab to pre-clinical to clinical applications.

\section{Acknowledgements:}

The authors acknowledge Amity Institute of Pharmacy, Amity University, Noida, Uttar Pradesh, India for providing FT-IR facility and Mankind Research Centre, Unit-3, Gurgaon, India providing DSC and XRD facility.

\section{Conflict of interests:}

The authors declared no conflict of interest.

\section{REFERENCES}

1. Lucas-Abellán C, Mercader-Ros MT, Zafrilla MP, Gabaldón JA, Núñez-Delicado E. Comparative study of different methods to measure antioxidant activity of resveratrol in the presence of cyclodextrins. Food Chem Toxicol 2011;49(6):1255-60.

2. Finkel T, Holbrook NJ. Oxidants, oxidative stress and the biology of ageing. Nature 2000;408(6809):239-47. 
3. Virgili F, Marino M. Regulation of cellular signals from nutritional molecules: A specific role for phytochemicals, beyond antioxidant activity. Free Radic Biol Med 2008;45(9):1205-16.

4. Schafer FQ, Buettner GR. Redox environment of the cell as viewed through the redox state of the glutathione disulfide/ glutathione couple. Free Radic Biol Med 2001;30(11):1191212.

5. Baur JA, Sinclair DA. Therapeutic potential of resveratrol: The in vivo evidence. Nat Rev Drug Discov 2006;5(6):493-506.

6. Gabaston J, Cantos-Villar E, Biais B, Waffo-Teguo P, Renouf $\mathrm{E}$, Corio-Costet MF, et al. Stilbenes from Vitis vinifera L. waste: A sustainable tool for controlling Plasmopara viticola. J Agric Food Chem 2017;65(13):2711-8.

7. Adrian M, Jeandet $\mathrm{P}$, Veneau J, Weston LA, Bessis R. Biological activity of resveratrol, a stilbenic compound from grapevines, against Botrytis cinerea, the causal agent for gray mold. J Chem Ecol 1997;23(7):1689-702.

8. Sobolev VS, Khan SI, Tabanca N, Wedge DE, Manly SP, Cutler $\mathrm{SJ}$, et al. Biological activity of peanut (Arachis hypogaea) phytoalexins and selected natural and synthetic stilbenoids. J Agric Food Chem 2011;59(5):1673-82.

9. Kristl J, Teskač K, Caddeo C, Abramović Z, Šentjurc M. Improvements of cellular stress response on resveratrol in liposomes. Eur J Pharm Biopharm 2009;73(2):253-9.

10. Miura D, Miura Y, Yagasaki K. Hypolipidemic action of dietary resveratrol, a phytoalexin in grapes and red wine, in hepatoma-bearing rats. Life Sci 2003;73(11):1393-400.

11. Xia N, Daiber A, Förstermann U, Li H. Antioxidant effects of resveratrol in the cardiovascular system. Br J Pharmacol 2017;174(12):1633-46.

12. Jiang Z, Chen K, Cheng L, Yan B, Qian W, Cao J, et al. Resveratrol and cancer treatment: Updates. Ann NY Acad Sci 2017;1403(1):59-69.

13. Shi Y, Zhou J, Jiang B, Miao M. Resveratrol and inflammatory bowel disease. Ann N Y Acad Sci 2017;1403(1):38-47.

14. Hou CY, Tain YL, Yu HR, Huang LT. The effects of resveratrol in the treatment of metabolic syndrome. Int $\mathrm{J}$ Mol Sci 2019;20(3):535.

15. Cadena PG, Pereira MA, Cordeiro RB, Cavalcanti IM, Neto $\mathrm{BB}$, Maria do Carmo CB, et al. Nanoencapsulation of quercetin and resveratrol into elastic liposomes. Biochim Biophys Acta Biomembr 2013;1828(2):309-16.

16. Amidon GL, Lennernäs H, Shah VP, Crison JR. A theoretical basis for a biopharmaceutic drug classification: The correlation of in vitro drug product dissolution and in vivo bioavailability. Pharm Res 1995;12(3):413-20.

17. Baur JA, Sinclair DA. Therapeutic potential of resveratrol: The in vivo evidence. Nat Rev Drug Discov 2006;5(6):493-506.

18. Walle T. Bioavailability of resveratrol. Ann N Y Acad Sci 2011;1215(1):9-15.

19. Walle T, Hsieh F, DeLegge MH, Oatis JE, Walle UK. High absorption but very low bioavailability of oral resveratrol in humans. Drug Metab Dispos 2004;32(12):1377-82.

20. Juan ME, Buenafuente J, Casals I, Planas JM. Plasmatic levels of trans-resveratrol in rats. Food Res Int 2002;35(2-3):195-9.

21. Amri A, Chaumeil JC, Sfar S, Charrueau C. Administration of resveratrol: What formulation solutions to bioavailability limitations? J Control Release 2012;158(2):182-93.

22. Jancova P, Anzenbacher P, Anzenbacherova E. Phase II drug metabolizing enzymes. Biomed Pap Med Fac Univ Palacky Olomouc Czech Repub 2010;154(2):103-6.
23. Wang P, Sang S. Metabolism and pharmacokinetics of resveratrol and pterostilbene. Biofactors 2018;44(1):16-25.

24. Ha ES, Choi DH, Baek IH, Park H, Kim MS. Enhanced oral bioavailability of resveratrol by using neutralized eudragit E solid dispersion prepared via spray drying. Antioxidants 2021;10(1):90.

25. Pignatello R, Pecora TM, Cutuli GG, Catalfo A, De Guidi $\mathrm{G}$, Ruozi B, et al. Antioxidant activity and photostability assessment of trans-resveratrol acrylate microspheres. Pharm Dev Technol 2019;24(2):222-34.

26. Silva AF, Monteiro M, Resende D, Braga SS, Coimbra MA, Silva A, et al. Inclusion Complex of Resveratrol with $\gamma$-Cyclodextrin as a Functional Ingredient for Lemon Juices. Foods 2021;10(1):16.

27. Savić-Gajić I, Savić IM, Nikolić VD, Nikolić LB, Popsavin MM, Rakić SJ. The improvement of photostability and antioxidant activity of trans-resveratrol by cyclodextrins. Adv Tech 2017;6(2):18-25.

28. Parveen S, Misra R, Sahoo SK. Nanoparticles: A boon to drug delivery, therapeutics, diagnostics and imaging. Nanomedicine 2012;8(2):147-66.

29. Jung JY, Yoo SD, Lee SH, Kim KH, Yoon DS, Lee KH. Enhanced solubility and dissolution rate of itraconazole by a solid dispersion technique. Int J Pharm 1999;187(2):209-18.

30. Fessi HP, Puisieux F, Devissaguet JP, Ammoury N, Benita $\mathrm{S}$. Nanocapsule formation by interfacial polymer deposition following solvent displacement. Int J Pharm 1989;55(1):R1-4.

31. Chaurasia S, Kumar N, Patel RR, Mishra B. Optimization of parameters for the fabrication of curcumin loaded polymeric nanoparticles using Taguchi robust design. Adv Sci Lett 2014;20(5-6):1028-38.

32. Waddad AY, Abbad S, Yu F, Munyendo WL, Wang J, Lv H, et al. Formulation, characterization and pharmacokinetics of Morin hydrate niosomes prepared from various non-ionic surfactants. Int J Pharm 2013;456(2):446-58.

33. D'Souza SS, DeLuca PP. Methods to assess in vitro drug release from injectable polymeric particulate systems. Pharm Res 2006;23(3):460-74.

34. Patel RR, Khan G, Chaurasia S, Kumar N, Mishra B. Rationally developed core-shell polymeric-lipid hybrid nanoparticles as a delivery vehicle for cromolyn sodium: Implications of lipid envelop on in vitro and in vivo behaviour of nanoparticles upon oral administration. RSC Adv 2015;5(93):76491-506.

35. Singh G, Pai RS, Pandit V. Development and validation of a HPLC method for the determination of trans-resveratrol in spiked human plasma. J Adv Pharm Technol Res 2012;3(2):130-5.

36. Wan L, Sun X, Li Y, Yu Q, Guo C, Wang X. A stereospecific HPLC method and its application in determination of pharmacokinetics profile of two enantiomers of naringenin in rats. J Chromatogr Sci 2011;49(4):316-20.

37. Buchanan CM, Buchanan NL, Edgar KJ, Little JL, Malcolm MO, Ruble KM, et al. Pharmacokinetics of tamoxifen after intravenous and oral dosing of tamoxifen-hydroxybutenyl- $\beta$ cyclodextrin formulations. J Pharm Sci 2007;96(3):644-60.

38. Re R, Pellegrini N, Proteggente A, Pannala A, Yang M, RiceEvans C. Antioxidant activity applying an improved ABTS radical cation decolorization assay. Free Radic Biol Med 1999;26(9-10):1231-7.

39. Khalil OA, de Faria Oliveira OM, Vellosa JC, de Quadros AU, Dalposso LM, Karam TK, et al. Curcumin antifungal and antioxidant activities are increased in the presence of ascorbic acid. Food Chem 2012;133(3):1001-5. 
40. Dillen K, Vandervoort J, Van den Mooter G, Ludwig A. Evaluation of ciprofloxacin-loaded Eudragit ${ }^{\mathbb{R}}$ RS100 or RL100/PLGA nanoparticles. Int J Pharm 2006;314(1):72-82.

41. Galindo-Rodriguez S, Allemann E, Fessi H, Doelker E. Physicochemical parameters associated with nanoparticle formation in the salting-out, emulsification-diffusion and nanoprecipitation methods. Pharm Res 2004;21(8):1428-39.

42. Uskokovic V. Entering the era of nanoscience: Time to be so small. J Biomed Nanotechnol 2013;9(9):1441-70.

43. Chakraborty S, Shukla D, Vuddanda PR, Mishra B, Singh S. Utilization of adsorption technique in the development of oral delivery system of lipid based nanoparticles. Colloids Surf B Biointerfaces 2010;81(2):563-9.

44. Mittal G, Sahana DK, Bhardwaj V, Kumar MR. Estradiol loaded PLGA nanoparticles for oral administration: effect of polymer molecular weight and copolymer composition on release behavior in vitro and in vivo. $\mathrm{J}$ Control Release 2007;119(1):77-85.

45. Sahana DK, Mittal G, Bhardwaj V, Kumar MR. PLGA nanoparticles for oral delivery of hydrophobic drugs: influence of organic solvent on nanoparticle formation and release behavior in vitro and in vivo using estradiol as a model drug. $\mathrm{J}$ Pharm Sci 2008;97(4):1530-42.

46. Govender T, Stolnik S, Garnett MC, Illum L, Davis SS. PLGA nanoparticles prepared by nanoprecipitation: drug loading and release studies of a water soluble drug. J Control Release 1999;57(2):171-85.

47. Govender T, Riley T, Ehtezazi T, Garnett MC, Stolnik S, Illum $\mathrm{L}$, et al. Defining the drug incorporation properties of PLAPEG nanoparticles. Int J Pharm 2000;199(1):95-110.

48. Panyam J, Williams D, Dash A, Leslie-Pelecky D, Labhasetwar V. Solid-state solubility influences encapsulation and release of hydrophobic drugs from PLGA/PLA nanoparticles. J Pharm Sci 2004;93(7):1804-14.

49. Chen Y, McCulloch RK, Gray BN. Synthesis of albumindextran sulfate microspheres possessing favourable loading and release characteristics for the anticancer drug doxorubicin. J Control Release 1994;31(1):49-54.

50. Chen Y, Mohanraj VJ, Parkin JE. Chitosan-dextran sulfate nanoparticles for delivery of an anti-angiogenesis peptide. Lett Pept Sci 2003;10(5-6):621-9.

51. Cui W, Li X, Zhou S, Weng J. Investigation on process parameters of electrospinning system through orthogonal experimental design. J Appl Polym Sci 2007;103(5):3105-12.

52. Bertacche V, Lorenzi N, Nava D, Pini E, Sinico C. Hostguest interaction study of resveratrol with natural and modified cyclodextrins. J Incl Phenom Macrocycl Chem 2006;55(3):279-87.

53. da Silva RD, Teixeira JA, Nunes WD, Zangaro GA, Pivatto M, Caires FJ, et al. Resveratrol: A thermoanalytical study. Food Chem 2017;237:561-5.

54. Kumar N, Chaurasia S, Patel RR, Kumar V, Mishra B. Development and optimization of atorvastatin calcium loaded oral biodegradable polymeric nanoparticles using central composite design. Adv Sci Lett 2014;20(5-6):984-93.

55. Zu Y, Zhang Y, Wang W, Zhao X, Han X, Wang $\mathrm{K}$, et al. Preparation and in vitro/in vivo evaluation of resveratrolloaded carboxymethyl chitosan nanoparticles. Drug Deliv 2016;23(3):971-81.

56. Kalita B, Das MK, Sarma M, Deka A. Sustained antiinflammatory effect of Resveratrol-Phospholipid complex embedded polymeric patch. AAPS PharmSciTech 2017;18(3):629-45.

57. Muthu MS, Singh S. Studies on biodegradable polymeric nanoparticles of risperidone: In vitro and in vivo evaluation. Nanomed 2008;3(3):305-19.

58. Wong C, Yuen K, Peh K. Formulation and evaluation of controlled release Eudragit buccal patches. Int J Pharm 1999; 178(1):11-22.

59. Bhagav P, Upadhyay H, Chandran S. Brimonidine tartrateeudragit long-acting nanoparticles: formulation, optimization, in vitro and in vivo evaluation. AAPS PharmSciTech 2011;12(4):1087-101.

60. Costa P, Lobo JM. Modeling and comparison of dissolution profiles. Eur J Pharm Sci 2001;13(2):123-33.

61. Korsmeyer RW, Gurny R, Doelker E, Buri P, Peppas NA. Mechanisms of potassium chloride release from compressed, hydrophilic, polymeric matrices: effect of entrapped air. J Pharm Sci 1983;72(10):1189-91.

62. Wang XQ, Dai JD, Zhang H, Zhang X, Wang JC, Zhang Q. Absorption mechanism of cyclosporine A loaded $\mathrm{pH}$-sensitive nanoparticles in rats. J Nanosci Nanotechnol 2008;8(5):242231.

63. Janssens S, De Zeure A, Paudel A, Van Humbeeck J, Rombaut P, Van den Mooter G. Influence of preparation methods on solid state supersaturation of amorphous solid dispersions: a case study with itraconazole and eudragit E100. Pharm Res 2010;27(5):775-85.

64. Jain AK, Swarnakar NK, Godugu C, Singh RP, Jain S. The effect of the oral administration of polymeric nanoparticles on the efficacy and toxicity of tamoxifen. Biomaterials 2011;32(2):503-15.

65. Lu X, Ji C, Xu H, Li X, Ding H, Ye M, et al. Resveratrolloaded polymeric micelles protect cells from $\mathrm{A} \beta$-induced oxidative stress. Int J Pharm 2009;375(1-2):89-96.

66. Re R, Pellegrini N, Proteggente A, Pannala A, Yang M, RiceEvans C. Antioxidant activity applying an improved ABTS radical cation decolorization assay. Free Radic Biol Med 1999;26(9-10):1231-7.

67. da Rocha Lindner G, Khalil NM, Mainardes RM. Resveratrolloaded polymeric nanoparticles: validation of an HPLC-PDA method to determine the drug entrapment and evaluation of its antioxidant activity. Sci World J 2013;2013.

68. Kim JH, Park EY, Ha HK, Jo CM, Lee WJ, Lee SS, et al. Resveratrol-loaded nanoparticles induce antioxidant activity against oxidative stress. Asian-Australas J Anim Sci 2016;29(2):288-98. 